\title{
The Effect of Increased Gastrin Release on Lower Esophageal Sphincter Pressure
}

\author{
Masatoshi Watanabe, Choichi Sugawa, ${ }^{*}$ Tetsuhiko \\ Hatafuku and Shozo Mori \\ Department of Surgery I, Iwate Medical University School \\ of Medicine, Morioka 020 and *Department of Surgery, \\ Wayne State University, Detroit, Michigan 48201
}

\begin{abstract}
Watanabe, M., Sugawa, C., Hatafuku, T. and Mori, S. The Effect of Increased Gastrin Release on Lower Esophageal Sphincter Pressure. Tohoku J. exp. Med., 1984, 144 (4), 377-384 — The present study was performed (1) to induce release of endogenous gastrin from the chronic isolated antrum, and (2) to note the effect of endogenous gastrin on lower esophageal sphincter pressure (LESP). Fifteen mongrel dogs weighing 15-20 kg were divided into 3 groups by the type of operation : 5 dogs with antral excision and B-II gastrojejunostomy (Group I) ; 5 dogs with a denervated antral pouch and B-II (Group II) ; and 5 dogs with an innervated antral pouch and B-II (Group III). Fasting serum gastrin levels (SGL) and LESP were determined preoperatively (basal) and at 2 and 4 weeks postoperatively. SGL was measured by radioimmunoassay using an antibody to human gastrin I. LESP was determined by pullthrough technique using an assembly of 3 polyvinyl tubes perfused with water at $0.6 \mathrm{ml} / \mathrm{min}$ and connected to external transducers. The mean SGL at 2 and 4 weeks after operation in Group I and in Group II were not significantly different from basal SGL. The SGL rose significantly at 2 weeks and 4 weeks in Group III $(p<0.05)$. The mean LESP at 2 and 4 weeks did not significantly change from the basal LESP in Group I, Group II and Group III. The present data show that (1) increased endogenous gastrin was produced only in the presence of an innervated antral pouch, and (2) the increased gastrin level, however, did not affect LESP. lower esophageal sphincter; endogenous gastrin; innervated antral pouch
\end{abstract}

The physiologic role of gastrin in raising lower esophageal sphincter pressure (LESP) remains controversial. Though exogenous gastrin in a pharmacologic dose has been reported to increase LESP (Lipschutz and Cohen 1971), it is dubious that such gastrin has an effect on LESP in physiologic doses. As regards the effect of endogenous gastrin on LESP, previous studies have shown that an increase in LESP is produced by gastrin release during gastric alkalinization (Castell and Harris 1970). On the contrary, there is a conflicting data that LESP dose not correlate with serum gastrin levels and gastric alkalinization has been

Received for publication, March 27, 1984. 
shown to increase LESP without affecting serum gastrin levels (Higgs et al. 1974). Recently, Kline et al. (1975), indicated that intragastric alkalinization or acidification did not increase total radioimmunoassayable serum gastrin levels and LESP in a controlled, blind study. Therefore, gastric alkalinization is questionable as a method to study the role of endogenous gastrin on LESP.

Antral pouch studies (Grossman et al. 1948; Woodward et al. 1954), a method to enhance endogenous antral gastrin release, has been utilized in a wide variety of experiments in studying the mechanism of gastric secretion. However, there are also conflicting results (Becker et al. 1973 ; Debas et al. 1974a) on whether antral alkalinization with a pouch releases gastrin. Friesen et al. (1974) demonstrated through an extensive experiment with dogs over a period of four years that an antral pouch with alkaline stimulation or gastric distension caused a significant elevation of serum gastrin concentration and gastric secretion.

The present study was designed to study the relationship between serum gastrin levels and LESP from a new aspect of antral alkalinization with a pouch. The objects were (1) to induce release of endogenous gastrin from the canine antrum, and (2) to evaluate more critically the gastrin on LESP.

\section{Materials and Methods}

Studies were performed on 15 mongrel dogs of both sexes weighing $15-20 \mathrm{~kg}$. They were divided into the 3 groups depending upon the type of operation (Fig. 1), as follows.

Group I Five dogs with antrectomy and gastrojejunostomy.

Group II Five dogs with denervated antral pouch and gastrojejunostomy.

Group III Five dogs with innervated antral pouch and gastrojejunostomy.

Three groups were provided to compare postoperative difference in serum gastrin levels and LESP at weekly intervals. At four weeks after operation, all the dogs were sacrificed and subjected to autopsy.

\section{Experimental Preparations}

The animals were fasted except water ad-lib for $24 \mathrm{hr}$ prior to each operation. Anesthesia was induced with sodium pentobarbital $(25-30 \mathrm{mg} / \mathrm{kg}$ ) and maintained with intermittent intravenous injections $(6 \mathrm{mg} / \mathrm{kg})$. After endotracheal intubation, positive pressure ventilation was maintained by a respirator (Harverd Apparatus, Model 607) using room air. Lactated Ringer's solution was given intravenously at the rate of $50 \mathrm{ml}$ per $\mathrm{hr}$

Group 1

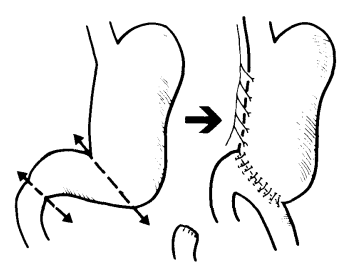

Group II

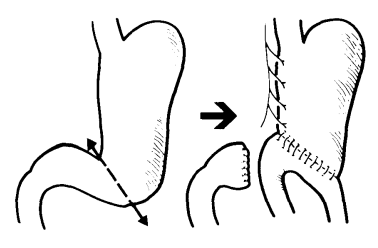

Group III

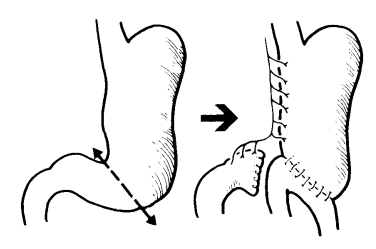

Fig. 1. Diagrammatic repesentation of the experimental preparations in Group I-III. Three groups were reconstructed with the fashion of Billroth II. 
during operation.

The abdomen was opened through a midline abdominal incision. The antrum was then transected carefully from the body of the stomach. Subsequently, in Group I, the antrum was excised and the duodenal stump was closed in usual fashion. In Group II, the antrum was transected completely at the corpoantral border including Laterget's fibers and a denervated antral pouch was prepared. In Group III, preparation was done in the same way as in Group II except that the care was taken to preserve the Laterget's fibers at the time of antral transection. In this way, both the antrum and antral innervation were preserved and the proximal end of the antral stump was closed by constructing an innervated antral pouch with intact blood supply. Finally, in all the groups, gastrointestinal continuity was restored by end-to-side gastrojejunostomy with Billroth II type, and the abdominal wall was closed. After operation, the animals were returned to their cages and received antibiotics as well as Lactated Ringer's solution $500 \mathrm{ml}$ per day for the first three days.

\section{Manometric studies}

Manometric studies to measure LESP were done in all the dogs prior to each operation and at weekly intervals during a month after operation. Immediately after blood samples for serum gastrin assay were taken, the dogs were anesthetized with $25-30 \mathrm{mg} / \mathrm{kg}$ of sodium pentobarbital, intubated and were studied in the supine position. Esophageal manometory was performed using an assembly of six polyvinyl catheters (Andorfer-McSteen Type, Argyle). In the present study, only three orifices were used which were located circumferentially at $5 \mathrm{~cm}$ from the distal tip and were radially oriented $120^{\circ}$ apart to minimize the effect of lower esophageal sphincter asymmetry. The remaining 3 orifices were closed and left unused.

Intraluminal pressures were transmitted to external transducers (Statham Instruments , Model P23Db) and graphed on a multichannel direct writting recorder (Hewlett Packard, Model $35-54 \mathrm{bN}$ ) at a paper speed of $1 \mathrm{~mm} / \mathrm{sec}$. The catheters were perfused continuously with water at $0.6 \mathrm{ml} / \mathrm{min}$ by a slow infusion system (Sag Instruments, Model 351). After the lower esophageal sphincter was identified by station pull-through, LESP was measured by a continuous pull-through technique at a withdrawal speed of $1 \mathrm{~mm} / \mathrm{sec}$.

LESP was taken at the midpoint between end-inspiratory and end-expiratory pressure, with gastric pressure serving as a zero reference point. LESP for each pull-through was calculated as the mean of the highest pressures recorded by each of the three sensors and was expressed as mmHg. Basal LESP was expressed at the mean LESP of all the dogs in each group which were measured before each operation.

\section{Serum Gastrin}

After an overnight fast, venous blood $(10 \mathrm{ml})$ for determination of serum gastrin concentration was taken from the jugular vein of each dog prior to manometric study. Blood samples were obtained before and after operation, at weekly intervals during a month. After clotting at room temperature, serum was obtained by centrifugation and was stored at $-20^{\circ} \mathrm{C}$ until assayed in duplicate. For determination of serum gastrin concentration of all blood samples, the radioimmunoassays with the resin-separation technique of McGuigan using an antibody to human gastrin I were done at Henry Ford Hospital. Basal serum gastrin concentration was expressed as the mean of all samples in each group taken before operation, and all gastrin concentrations were expressed as $\mathrm{pg} / \mathrm{ml}$.

\section{Statistics}

Data were presented as absolute values of LESP and serum gastrin concentration. Mean values and standard errors (S.E.) of the mean were calculated for individual value in each group. Differences in mean values tested for significance by paired t-test and $\mathrm{P}$ values less than 0.05 were considered as significant. 


\section{Results}

Fig. 2 summarizes the serum gastrin concentrations in each group before and after operation. The mean basal serum gastrin concentration was $66.0 \pm 6.4 \mathrm{pg} / \mathrm{ml}$ in Group I, $63.6 \pm 5.6 \mathrm{pg} / \mathrm{ml}$ in Group II, and $63.4 \pm 8.1 \mathrm{pg} / \mathrm{ml}$ in Group III respectively, and there were no significant differences among these values. The mean serum gastrin in Group III at 2 and 4 weeks after operation were $150.1 \pm 82.9 \mathrm{pg} /$ $\mathrm{ml}$ and $173.0 \pm 78.3 \mathrm{pg} / \mathrm{ml}$ respectively, and these were significantly different from the corresponding mean serum gastrin concentrations in Group I and Group II. In addition, the rise in the mean serum gastrin in Group III after operation showed significant differences as compared with its mean basal serum gastrin. Otherwise, there was little change in the pre- and postoperative mean serum gastrin in Groups I and II.

The mean LESP in each group before and after operation are summarized in Fig. 3. The mean basal LESP was $13.6 \pm 1.8 \mathrm{mmHg}$ in Group I, $13.0 \pm 1.8 \mathrm{mmHg}$ in Group II and $15.6 \pm 5.1 \mathrm{mmHg}$ in Group III, respectively. There was no significant difference in the mean basal LESP among each group. In Group I, the mean LESP at both 2 and 4 weeks after operation were not significantly different

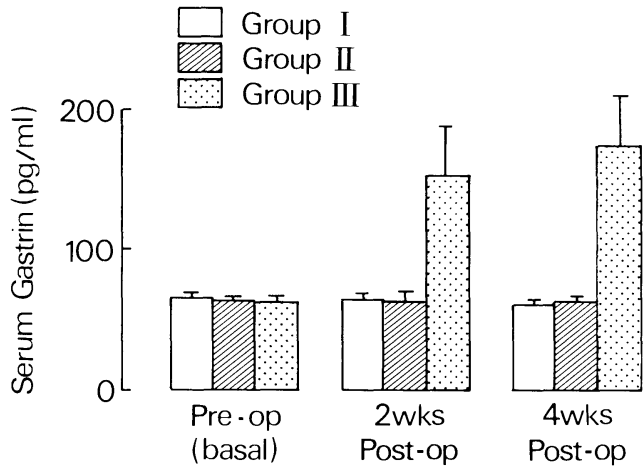

Fig. 2. Mean serum gastrin concentrations in 3 groups consisting of 5 dogs for each before and after operation. Vertical lines represents S.E.

Fig. 3. Mean lower esophageal sphincter pressure (LESP) in the 3 groups presented in Fig. 2 before and after operation. Vertical lines represents S.E.

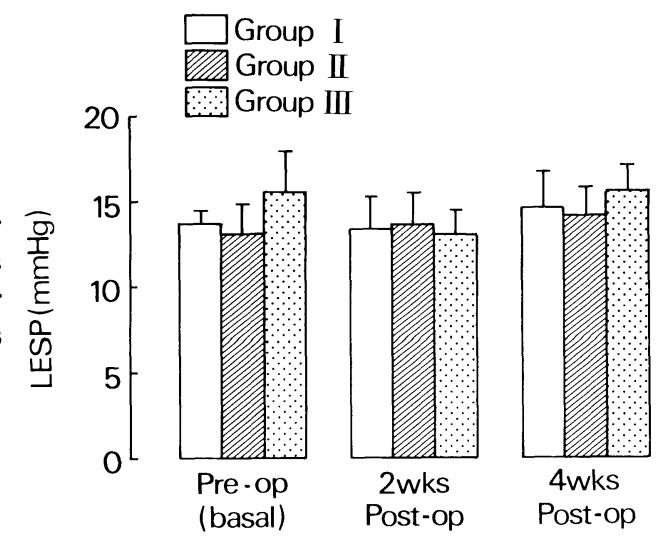


from its mean basal LESP. Furthermore, in Group I, II and III, there were no significant differences between the pre- and postoperative mean LESP. At autopsy, all the dogs grossly showed no finding of reflux esophagitis.

These results indicate that the rise in serum gastrin concentration was obtained only in Group III with innervated antral pouch, and also there was no correlation between serum gastrin concentration and LESP. Moreover, antral excision had no effect on serum gastrin concentration and LESP.

\section{Discussion}

The results of the present study confirmed a previous observation (Friesen et al. 1974) that chronic antral pouch was an effective means of raising serum gastrin concentration. However, the previous study did not state whether antral innervation was presented or not. Moreover, the present study provides a more precise evaluation regarding the difference in serum gastrin concentrations between the innervated and denervated antral pouch, because a significant increase in serum gastrin concentration could be obtained only with innervated antral pouch.

On the other hand, other pouch studies (PeThein and Schofield 1962; Woodward et al. 1957) failed to show clearly whether antral alkalinization stimulated acid secretion and supported increased release of endogenous gastrin. Landor (1966) suggested that denervated antral pouch might elaborate gastrin despite the absence of known stimuli for gastrin release observing descreased daily secretion and the lowered response to histamine stimulation after antral resection. Recently, Debas et al. (1974b), reported an acute pouch study in which an increment of serum gastrin in response to antral distension with alkali was observed only with innervated antral pouch but not with dennervated antral pouch which accords with our results. Though gastric alkalinization has been utilized widely to raise serum gastrin concentration (Nebel and Castell 1973; Lipshutz et al. 1972 ; Picker and Brenner 1972), it may not be suitable to evaluate the relationship between serum gastrin concentration and LESP becuse of the lack of evidence whether serum gastrin can certainly be raised by alkalinization. In acute gastric or antral alkalinization, a combination of alkalinization and distension of the antrum seems needed for the release of endogenous gastrin (Debas et al. $1974 \mathrm{~b})$. In the present study, the presence of bile in the innervated antral pouch without distension seen at autopsy suggests that chronic antral pouch preparation can be expected to result in enhanced antral gastrin release without artificial stimuli. Therefore, the present study demonstrates that the chronic innervated antral pouch preparation can be a method to obtain a rise in endogenous serum gastrin.

Concerning the relationship between the rise in serum gastrin and LESP, exogenous gastrin such as gastrin 17 is capable to increase LESP but only in a pharmacologic dose (Cohen and Lipshutz 1971). Recently, it was reported, however, that gastrin 17 when administered in physiologic doses failed to increase 
LESP (Freeland et al. 1976 ; Jennewein et al. 1976). The present study revealed that LESP showed little changes in each group though the significant elevation of serum gastrin concentration was observed in Group III with innervated antral pouch. These results suggest that increased endogenous gastrin has no effect on LESP since we found no association between LESP and elevated serum gastrin levels. However, this finding conflicts markedly with previous observations (Nebel and Castell 1973; Lipshutz et al. 1972; Picker and Brenner 1972) that gastric alkalinization using alkali instillation caused increased gastrin levels and resulted in an increase in LESP. More recently, Kline and co-workers (1975) indicated that such gastric alkalinization did not raise serum gastrin levels or LESP, in a controlled and blind study comparing the effect of alkali and acid on the LESP. Furthermore, our results support a previous report by McCallum and Walsh (1979), in that neither physiologic nor pathologic variations in serum gastrin concentration were shown to influence regulation of basal LESP in patients with Zollinger-Ellison syndrome.

It is questionable whether radioimmunoassay is able to measure biologically active gastrin and analyze it according to the different molecular fractions. Several fractions of gastrin have been identified in human gastrin (Yalow and Berson 1971). In this study, increase in total serum gastrin concentrations indicated that the release of endogenous gastrin was induced by innervated antral pouch, although its molecular fraction and biologic activity have remained unclear. These points may be solved by determinating and analyzing the extract from innervated antral pouch biologically and physiologically. Therefore, further studies are obviously needed to clarify these specific points.

In Group I with antrectomy, serum gastrin levels and LESP were not changed as compared with the basal serum gastrin levels and LESP. These findings suggest that both serum gastrin levels and LESP may be independent of the antral regulations at least in fasting and unstimulated periods. These observations support a previous study by Siewert et al. (1974), where patients had undergone antrectomy and gastrojejunostomy, and no difference in LESP and serum gastrin levels were shown between patients and controls in the fasting period. In contrast, Eckardt et al. (1978), reported that no significant difference in resting LESP was found between the patients with peptic ulcer disease, whereas patients with antrectomy had significantly lower serum gastrin levels when compared with unoperated controls. The difference in serum gastrin levels may be renderd to the difference in the selected subjects and the method of anastomosis with gastroduodenostomy, but no with gastrojejunostomy.

In summary, the present study indicates that a significant increase in serum gastrin levels, as evidenced only with innervated antral pouch, does not affect LESP. Serum gastrin levels and LESP in the fasting subjects were independent of the antral regulations as shown by the absence of difference in serum gastrin levels after antrectomy. 


\section{References}

1) Becker, H.D., Reeder, D.D. Thompson, J.C. (1973) The effect of changes in antral pH on the basal release of gastrin. Proc. Soc. exp. Biol. Med., 143, 238-240.

2) Castell, D.O. Harris, L.D. (1970) Hormonal control of gastroesophageal-sphincter strength. N. Engl. J. Med., 282, 886-889.

3) Cohen, S. \& Lipshutz, W. (1971) Hormonal regulation of human lower esophageal sphincter competence: interaction of gastrin and secretin. J. clin. Invest., 50, 449454 .

4) Debas, H.T., Csendes, A., Walsh, J.H. Grossman, M.I. (1974a) Release of antral gastrin. In: Endocrinology of the Gut, edited by F.P. Brooks \& W.Y. Chey, Thorofare, New Jersey, Charles B Slack Inc., pp 222-232.

5) Debas, H.T., Konturek, S.J., Walsh, J.H. Grossman, M.I. (1974b) Proof of a pylorooxyntric reflex for stimulation of acid secretion. Gastroenterology, 66, 526-532.

6) Eckardt, V.F., Grace, N.D., Osborne, M.P., Fisher, J.E. (1978) Lower esophageal sphincter pressure and serum gastrin levels after mapped antrectomy. Arch. intern, Med., 138, 243-245.

7) Freeland, G.R., Higgs, R.H. Castell, D.O. (1976) Lower esophageal sphincter and gastric acid responses to intravenous infusions of synthetic human gastrin heptadecapeptide I. Gastroenterology, 71, 570-574.

8) Friesen, S.R., Crosby, I., Boggan, M.D., Fiallos, E., Lees, J.M., Cudnik, D.B., Bolinger R.E. McGuigan, J.E. (1974) An experimental study of the antral gastrin mechanism. Surgery, 75, 517-527.

9) Grossman, M.I., Robertson, C.R. \& Ivy, A.C. (1948) Proof of a hormonal mechanism for gastric secretion: the humoral transmission of the distention stimulus. Amer. $J$. Physiol., 153, 1-9.

10) Higgs, R.H., Smyth, R.D. Castell, D.O. (1974) Gastric alkalinization: Effect on lower-esophageal sphincter and gastrin. New Engl. J. Med., 291, 486-490.

11) Jennewein, H.M., Hummelt, H., Siewert, R. Waldeck, F. (1976) The effect of intravenous infusion of synthetic human gastrin-I on lower esophageal sphincter (LES) pressure in the dog and its relation to gastrin level. Digestion, 14, 376-380.

12) Kline, M.M., McCallum, R.W., Curry, N. \& Sturdevant, R.A. (1975) Effect of gastric alkalinization on lower esophageal sphincter pressure and serum gastrin. Gastroenterology, 68, 1137-1139.

13) Landor, J.H. (1966) Evidence for gastrin release by the unstimulated, isolated antral pouch. Surgery, 60, 641-646.

14) Lipschutz, W. Cohen, S. (1971) Physiologic determinants of lower esophageal sphincter function. Gastroenterology, 61, 16-24.

15) Lipshutz, W., Hughes, N. \& Cohen, S. (1972) The genesis of lower esophageal sphincter pressure: its identification through the use of gastrin antiserum. J. clin, Invest., 51, 522-529.

16) McCallum, R.W. \& Walsh, J.H. (1979) Relationship between lower esophageal sphincter pressure and serum gastrin concentration in Zollinger-Ellison syndrome and other clinical setting. Gastroenterology, 76, 76-81.

17) Nebel, O.T. \& Castell, D.O. (1973) Inhibition of the lower esophageal sphincter by fat: a mechanism for fatty food intolerance. Gut, 14, 270-274.

18) PeThein, M. Schofield, B. (1962) Biphasic feeding responses in separated fundic pouches in dogs and their relation to the pyloric antrum. Gastroenterology, 43, 436447.

19) Picker, B.B.S. \& Brenner, C.G. (1972) The effect of intragastric aluminum hydrooxide on lower esophageal sphincter pressures. S. Afr. Med. J., 216, 1387-1389.

20) Siewert, R., Koch, A., Stuhler, T.H. \& Jenne Wein, H.M. (1974) Kardiafunktion und 
gastroesophagealer Reflux nach distaler Magenresection. Z. Gastroent., 12, 583-590.

21) Woodward, E.R., Lyon, E.S., Landor, J.H. \& Dragestedt, L.R. (1954) The physiology of the gastric antrum. Experimental studies on isolated antrum pouches in dogs. Gastroenterology, 27, 766-785.

22) Woodward, E.R., Robertson, C., Fried, W. \& Schapiro, H. (1957) Further studies on the isolated gastrin antrum. Gastroenterology, 32, 868-877.

23) Yalow, R.S. \& Berson, S.A. (1971) Further studies on the nature of immunoreactive gastrin in the human plasma. Gastroenterology, 60, 203-214. 